\title{
Apresentação
}

Eloisa Acires Candal Rocha ${ }^{\mathrm{i}}$

O apanhador de desperdícios

Dou respeito às coisas desimportantes

$\mathrm{E}$ aos seres desimportantes

Tenho em mim um atraso de nascença Eu fui aparelhado para gostar de passarinhos

Tenho abundância de ser feliz por isso

Meu quintal é maior que o mundo

Sou um apanhador de desperdícios

(BARROS, 2004)

A publicação desta Revista Artes de Educar, com o Dossiê: Bebês e criança: cultura, linguagens e políticas, organizado por Anelise Monteiro de Nascimento, Nazareth Salutto e Sílvia Néli Falcão Barbosa nos inspira a revisitar alguns excertos destes lindos versos de Manuel de Barros, dando valor às coisas e aos seres desimportantes por dois motivos. Primeiro, porque nos permite parodiar o próprio lugar das crianças no interesse científico na história, depois porque ilustra o momento presente, em que vivemos as consequências de uma pandemia global, com restrição de convívio social e suspensão de atividades tidas como corriqueiras e importantes. Os bebês e as crianças bem pequenas não se constituíram um tema no rol dos interesses científicos. O bebê parecia ter um grau de importância correspondente ao seu tamanho, só ganhando valor ao ser estudado em sua potência como germe de um adulto no futuro.

Há pouco mais de 20 anos é que começa a se consolidar uma preocupação científica com os bebês e crianças pequenininhas e os processos educativos que lhes constituem em contextos coletivos de educação (creche). Com se sabe, a tradição anterior de estudos sobre as crianças preocupou-se apenas com os parâmetros do processo de desenvolvimento, da linguagem, crescimento físico e condições de crescimento, com pouca atenção aos determinantes dos novos contextos sociais, que passaram a integrar a vida das crianças na maior parte das sociedades urbanas, principalmente desde o século XX.

\section{(ब) (๑)}

2020 Bargas; Ayoub; Assaritti, Scarazzatto, Assis. Este é um artigo de acesso aberto distribuído sob os termos da Licença Creative Commons Atribuição Não ComercialCompartilha Igual (CC BY-NC-4.0), que permite uso, distribuição e reprodução para fins não comerciais, com a citação dos autores e da fonte original e sob a mesma licença 
Nos últimos dez anos, porém, vimos um crescimento significativo dos estudos e pesquisas com bebês nesses contextos educativos. A publicação deste Dossiê coincide com um momento fundamental para a produção do conhecimento sobre formas de vida das crianças no contexto contemporâneo e as responsabilidades sociais sobre elas. Torna-se urgente a construção de perspectivas educativas qualificadas para suas experiências como seres humanos de pouca idade. Encontramo-nos num tempo de inflexão no qual urge questionar as bases políticas, éticas e estéticas dos projetos para as crianças, sobretudo com elas, num desvio de caminho, na mais firme direção dos “despropósitos" em "respeito às coisas desimportantes", para quiçá "alcançar um quintal maior que o mundo".

Assim é que os textos que integram esta publicação ganham uma força ainda maior ao produzirem um eco no estabelecimento de novos propósitos para as novas gerações. O que realmente importa para a experiência humana no início da vida? E agora, no depois (pós pandemia), que espaços e tempos se apresentam para a constituição de uma vida vivida no coletivo? Qual a possibilidade da alegria, da solidariedade, da cooperação na sociabilidade das instituições responsáveis pelas crianças pequenas e bebês?

Talvez nunca, desde a Ciência Moderna, o estudo da infância tenha chegado a um sentido tão profundo, exigindo uma intensa revisão dos valores e prioridades vitais, motivados pela experiência de isolamento gerada pela pandemia global, mas não só, marcados também pelas evidências do esgotamento e exploração dos recursos naturais, regidos pelos modelos econômicos pautados no lucro. As consequências da acumulação da riqueza em detrimento da igualdade social no mundo, e as disparidades de condições e direitos para uma vida digna e plena, nos coloca ainda mais no centro de um questionamento crítico e de um necessário reposicionamento de valores e ideais dirigidos às novas gerações.

Momento em que novos sentidos e significados se apresentam para o campo da pesquisa nas Ciências Humanas e Sociais e, sobretudo, no campo das pesquisas sobre e com as crianças, seus contextos de vida e educação e modos de inserção no mundo (aliás, que mundo?)

Como "uma onda no ar" os textos aqui apresentados vêm somar-se a algumas publicações acadêmicas recentes no Brasil, que surpreendentemente expressam um adensamento dos estudos em torno dos bebês, das crianças bem pequenas 1 .

\footnotetext{
${ }^{1}$ Ver, em especial, o Dossiê da Revista de Educação da Unisinos: "Educação Infantil: em questão as crianças de 0 a 3 anos e a creche", organizado por Catarina Moro e Mônica Appezzato Pinazza (2020); e o livro: "Estudos de bebês e diálogos com a Sociologia", organizado por Gabriela Tebet, São Carlos: Pedro e João editores, 613p. 2019.
}

Revista Interinstitucional Artes de Educar. Rio de Janeiro, V. 6, N.2- pág. 444-451 maio-agosto de 2020: "Bebês e crianças: cultura, linguagem e políticas" 
Aliás, perguntamo-nos quem deveria, de fato, assumir tal responsabilidade política, econômica, social e cultural pelo desenvolvimento da vida das novas gerações? Quem são os adultos e profissionais que têm esta tarefa e quais os princípios que orientarão sua ação social com as crianças dentro e fora das instituições educativas, de forma a produzir uma reconfiguração significativa da educação no início da vida, no recomeço dos tempos?

Assim é que a publicação deste Dossiê traz importantes contribuições. para estas questões atuais, a partir de princípios antes já proclamados, mas agora retomados e potencializados. Sua pertinência expressa o trabalho de suas próprias organizadoras, Anelise Monteiro do Nascimento; Nazareth Salutto e Sílvia Néli Falcão Barbosa, pesquisadoras da infância comprometidas em articular a investigação científica com a formação das profíssionais da atuação direta com os bebês e as crianças pequenas e as indicações para suas práticas na direção da participação e da emancipação.

Os textos aqui reunidos têm como preocupação central os bebês e as crianças nas dimensões da educação, da cultura, das linguagens e das políticas. Neste caminho, o Dossiê abre com um primeiro texto sobre as perspectivas estéticas analisadas no âmbito do teatro com bebês.

O estudo, elaborado por Luiz Miguel Pereira e Jader Janer Moreira Lopes, tem como principal referência estudos bakhtinianos, e trata de uma possibilidade enunciativa em torno de "brincadeiras cênicas" entre os bebês em contexto de relações coletivas, a partir da oferta de uma ambientação cenicamente elaborada. Este desenvolvimento permitiu observar "aparecimento dos processos de imitação, de reelaboração criadora composto de movimentos irrepetíveis, dando espaço para uma produção intersubjetiva, numa relação de horizontalidade dos participantes bebês".

O corpo infantil é também objeto do segundo texto deste Dossiê, Celebrando a normatização da vida: (re)pensando os corpos infantis arbitrariamente genereficados em vídeos de "chás de revelação" do Youtube, de Dilton Ribeiro Couto Junior, Ivan Amaro, Renato Romeritto e Ruann Moutinho Ruani. Os autores trazem à tona as recentes práticas sociais de descoberta da definição do sexo do bebê, ainda em gestação, num estudo muito original sobre vídeos publicados em uma rede social. As análises indicam que há uma reprodução que normatiza os corpos e gêneros das crianças, desconsiderando que cada criança que nasce traz consigo outras possibilidades de agir. Os autores alertam para a necessidade de planejarmos práticas pedagógicas que questionem uma ordem social e cultural que policia os corpos e nos 


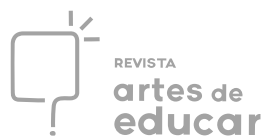

impede de enxergar a infância, a educação, a vida e o mundo para além dos binarismos, que violam direitos e são produtores de práticas sexistas e racistas.

A vida dos bebês e das crianças é marcada pela ação social dos adultos, particularmente quando esta ação se dá em espaços institucionalizado de compartilhamento dos cuidados e educação, como a creche.

Isto resulta numa prática profissional com especificidades próprias, que já foram anteriormente definidas como uma docência marcada pela sutileza (Tristão, 2004) e como uma ação necessariamente compartilhada com outros (Duarte, 2011). Esta complexidade de ser professora de bebês é tema de dois textos deste Dossiê: A docência na creche: entre a simplicidade e a complexidade sutil, de Rachel Arenari e Patrícia Corsino; e A solidão profissional de professores de bebês, de Marlene Oliveira dos Santos. O primeiro conclui, a partir de um estudo da produção acadêmica brasileira em diálogo com autores da pedagogia, que a docência na creche "exige do docente sensibilidade, possibilidade de escuta e de resposta, além de estudo, reflexões individuais e coletivas, criatividade na organização de contextos provocativos, que favoreçam a brincadeiras, ações e interações". O segundo texto resulta de uma pesquisa que envolve a escuta de professoras através de narrativas e afirma estas como possibilidades formativas que permitem "partilha de ideias, descobertas, conquistas, angústias e dificuldades experienciadas no exercício da docência com os bebês, bem como espaço de autoafirmação de cada professora como mulher, como autora de conhecimentos oriundos de sua itinerância pessoal-formativa, do seu saber fazer e das experiências das crianças".

Desta forma, o conjunto de estudos do Dossiê vai tecendo uma trama teórico-prática que subsidia o enfrentamento das demandas educativas do tempo presente, encontrando um elo comum em princípios de formação humana voltados para os mais novos. Princípios que reiteram a centralidade do brincar, da interação e das relações com crianças e bebês nos processos educativos e retomam as culturas infantis como base do lugar da infância nos espaços educacionais, incluindo a necessária crítica e autocrítica de orientações educativas, também traduzidas em documentos oficiais.

Os modelos e orientações pedagógicas são objeto de estudo de outros três textos do Dossiê. Um primeiro deles, Modelos pedagógicos explícitos e a construção de uma pedagogia para bebês e crianças bem pequenas baseados no brincar, de Alessandra G. de Oliveira, busca modelos pedagógicos em diferentes teóricos para definir elos comuns de qualidade em creche. A autora encontra convergências nas teorias analisadas relativas à agência do bebê e da criança, no

Revista Interinstitucional Artes de Educar. Rio de Janeiro, V. 6, N.2-pág. 444-451 maio-agosto de 2020: "Bebês e crianças: cultura, linguagem e políticas" 
respeito ao período sensório-motor; enfatizando a relevância dos espaços; materiais e interações responsivos a sua curiosidade e necessidade exploratória; ao considerar como brincadeiras as interações do bebê com o adulto, com seu próprio corpo, com objetos e também com seus pares.

A importância dos espaços na creche também é analisada pelo texto Os espaços dos bebês na creche: o que dizem os documentos do MEC, por Giseli Alcassas Masson e Jarina Rodrigues. O estudo localiza uma extensa presença do tema em diferentes documentos oficiais que permitem concluir uma concepção de espaço como aquele que "educa" os bebês e os educadores e que também são educados por eles, como uma perspectiva transformadora a ser vivenciada nas creches.

O texto seguinte coloca em questão as condições profissionais e pedagógicas para frequência à creche por crianças surdas. Ao realizar um estudo de caso entre a creche e a família, o texto A educação na orientação de pais e bebês de crianças surdas, de Erica Aparecida Garutti Lourenço; Sandra Regina Leite de Campos; Jéssica de Oliveira Holanda, revela o papel da mediadora pedagógica como determinante para apresentação da língua de sinais, não somente para a criança surda, mas para os outros (crianças não surdas, profissionais e professoras e família). O estudo "demonstrou, nas suas vivências, a criança como sujeito de interação; foi a profissional que exerceu a escuta atenta à criança, percebendo nela os benefícios de uma interlocução na Libras e na apreensão e relacionamento com o mundo por formas visuais prioritariamente, como no planejamento de recursos e estratégias que garantissem alguma participação sua na rotina da turma".

As condições oferecidas para os bebês participarem e terem autonomia no contexto da creche também são abordadas no texto Uma perspectiva para acompanhar o processo dos bebês de conquista da autonomia na creche, de Angela Scalabrin Coutinho e Daniele Marques Vieira. As sequências apresentadas no texto "buscam narrar visualmente o processo de conquista da autonomia vivenciado por uma bebê em um dado contexto, com o objetivo de apresentar uma perspectiva de educação que toma o bebê como um ator social competente, e a partir dessa ideia cria condições para que essa competência encontre respaldo para o seu desenvolvimento". Tratase de mais um artigo que vem consolidar nesta publicação a indicação de caminhos pedagógicos na direção da emancipação humana. Para as autoras "a autonomia se sustenta como um princípio que orienta a ação adulta na mediação da liberdade de ação das crianças, de modo singular, e pautada na observação atenta, cuidadosa e sistemática das vivências infantis".

Revista Interinstitucional Artes de Educar. Rio de Janeiro, V. 6, N.2-pág. 444-451 maio-agosto de 2020: "Bebês e crianças: cultura, linguagem e políticas" 
O texto Os bebês e a creche: reflexões sobre o direito à qualidade das interações, de Edilane Oliveira da Silva; Lívia Larissa de Lima Lage e Michelle Dantas Ferreira, toma a empiria de um cotidiano de berçário para refletir sobre estas mesmas possibilidades de interação no contexto coletivo da creche. Afirmam que, "quando este outro é um ser tão misterioso, potente e simultaneamente vulnerável quanto é o bebê, as interações se tornam ainda mais fundamentais". E atribuem especial destaque ao que outros textos aqui publicados também enfatizaram, indicando que é necessário "pensar sobre o cuidado com quem cuida e compreender quais são as condições que favorecem ou inibem uma presença atenta, delicada e dedicada das educadoras com os bebês/educandos e problematizar as condições nas quais trabalham as educadoras de bebês".

As concepções identificadas neste conjunto de textos retomam e recolocam as bases e fundamentos que vem sendo tecidos na produção acadêmica nacional que já vinha buscando dar centralidade às culturas infantis, tal como aponta o estudo Bebês e crianças bem pequenas no debate sobre cultura infantil, de Andrea Braga Moruzzi e Giovana Alonso. Este movimento teórico questiona o lugar de subalternidade dos bebês "ao considerar-se que nem sempre suas culturas são valorizadas e suas linguagens respeitadas. Uma cultura sobre a infância, hegemônica e adultocentrica, tende a silenciar a agência, o protagonismo e a cultura infantil”".

O texto seguinte, A infância a partir dos dizeres e fazeres das crianças na escola: encontros silenciosos e potentes, de Nádia Priscila de Lima Carvalho, Fernanda Maria Santos Albuquerque e Conceição Gislane Nóbrega Lima de Salles, ainda que tenha como foco crianças maiores mantém a mesma preocupação de análise sobre os espaços para a infância em contextos educativos escolares. Ancorado no campo da filosofia, considerando a infância como experiência, situam os dizeres e fazeres das crianças e suas experiências como "resistentes e ousadas". Indica uma ação educativa na qual "precisamos semear meios de escuta e olhar mais aguçados e portadores de respeito quanto a tudo que as crianças têm a nos dizer e a nos mostrar". Demarca-se como um texto prudente para estes tempos que nos exigem criar uma (re)existência.

Os artigos de fluxo contínuo desta publicação se referem, um à literatura, ao letramento literário na formação de professores, e outro, às representações da criança negra na literatura.

O texto: Formando professores e também leitores: práticas de letramento literário com licenciados em Pedagogia, de Ailton Ferreira da Rosa Junior, apresenta uma experiência formativa, no sentido de "demonstrar aos futuros professores como usufruir da potência da 
dimensão humanizadora da literatura", e coloca em questão os repertórios culturais de licenciados que serão responsáveis pela educação de crianças.

O artigo: A Literatura infanto juvenil e música: representação da criança negra e abordagens da alteridade na França e no Brasil, de Véronique Francis e Valéria Barbosa, toma um estudo comparativo com base na literatura e na música presentes nas escolas dos dois países em pauta. As autoras colocam em questão aspectos estruturais da sociedade e que exigem colocar no centro do debate a alteridade. Afirmam que é necessário "considerar a alteridade desses sujeitos em suas múltiplas dimensões de modo a superar estereótipos para que o pertencimento das crianças a uma identidade que seja respeitada a partir de sua inserção na sociedade complexa e envolve relações sociais de classe, raça e gênero".

Os textos que compõem a sessão de relatos de experiências têm como foco uma reflexão sobre o lugar dos bebês na relação educativa a partir da experimentação de seus corpos em movimento. Dois relatos que inspiram perspectivas pedagógicas para muito além de práticas limitantes ou conformadoras, reafirmam a potência de ação das crianças como partícipes de sua própria experiência educativa. O primeiro deles, Performance com bebês: deitar e rolar, de Fernanda Paixão, coloca especialmente em destaque uma reflexão "sobre o que pode ser esse estado performativo" com crianças bem pequenas, ressignificando o conceito de infantilização, como uma "maneira de perceber na infância as condições de possibilidade de invenção de novos modos de vida". Já o relato, As aventuras (des)formativas no agenciamento dançarino-criança, de Andrea Nascimento, tem como uma de suas referências Foucault, ao afirmar" os modos de ativos de constituição do sujeito por meio de práticas de si”, propostos e sugeridos pelas relações sociais.

A indagação, que educação e para quem? Presente em alguns artigos permanece um desafio para os "novos" tempos, sobretudo em contextos de extrema desigualdade social que marcam a vivência da infância. Este é o retrato que ganha evidência na resenha de Amanda Pontes Figueiredo, Fernanda De Almeida e Flávia Fernanda Ferreira De Lucena, sobre o original, forte e delicado livro: Infância crônica, organizado por Raíza Venas e Rita Ribes. Publicado pela Editora NAU no ano de 2019, reúne uma coletânea de 35 crônicas escritas por pesquisadores que compõem o Grupo de Pesquisa Infância e Cultura Contemporânea, no projeto "Fisionomias da infância: experiências cotidianas, alteridades e deslocamentos", desenvolvido na Faculdade de Educação da Universidade Estadual do Rio de Janeiro - UERJ.

Revista Interinstitucional Artes de Educar. Rio de Janeiro, V. 6, N.2- pág. 444-451 maio-agosto de 2020: "Bebês e crianças: cultura, linguagem e políticas" 
Finalizando a publicação e com uma maravilhosa forma de somarmos forças para “apanhar desperdícios” segue a Entrevista com Sonia Kramer, intelectual e pesquisadora da educação e da infância, que detém uma incomensurável contribuição para a teorização e a formação de pesquisadores e professores para a infância, lança luzes e esperanças para as novas aprendizagens e desafios postos pelo presente para o futuro das relações entre bebês, crianças e adultos. Anuncia Kramer: Vamos precisar estar preparados para brincarmos muito!!!

\section{REFERÊNCIAS}

BARROS, Manoel. Livro sobre nada. São Paulo: Record, 1996.

${ }^{\text {i }}$ Professora e pesquisadora aposentada da UFSC, NUPEIN/CED. E-mail: eloisa.rocha@ufsc.br / ORCID: http://orcid.org/0000-0001-9540-5200

Revista Interinstitucional Artes de Educar. Rio de Janeiro, V. 6, N.2-pág. 444-451 maio-agosto de 2020: "Bebês e crianças: cultura, linguagem e políticas" 